ANL/ED/CP - $950 \mathrm{b7}$

\title{
RADIATION DAMAGE OF A GLASS-BONDED ZEOLITE WASTE FORM USING ION IRRADIATION
}

by

B. G. Storey and T. R. Allen

Argonne National Laboratory-West

P.O. Box 2528

Idaho Falls, ID 83403-2528

The submitted manuscript has been created : by the University of Chicago as Operator of. Argonne National Laboratory (Argonne") : under Contract No. W-31-109-ENG-38 with the U.S. Department of Energy. The U.S. Government retains for itself, and others acting on its behall, a paid-up, nonexclusive, irrevocable morldwide license in said article to reproduce, prepare derivative works, distribute copies to the public, and perform publicly and display publicly, by or on behall of the Government.

Paper to be submitted for presentation at the Materials Research Society Fall 1997 Meeting

Boston, Massachusetts

December 1-5, 1997

*Work supported by the U.S. Department of Energy Contract W-31-109-ENG-38. 


\section{DISCLAIMER}

This report was prepared as an account of work sponsored by an agency of the United States Government. Neither the United States Government nor any agency thereof, nor any of their employees, make any warranty, express or implied, or assumes any legal liability or responsibility for the accuracy, completeness, or usefulness of any information, apparatus, product, or process disclosed, or represents that its use would not infringe privately owned rights. Reference herein to any specific commercial product, process, or service by trade name, trademark, manufacturer, or otherwise does not necessarily constitute or imply its endorsement, recommendation, or favoring by the United States Government or any agency thereof. The views and opinions of authors expressed herein do not necessarily state or reflect those of the United States Government or any agency thereof. 


\section{DISCLAIMER}

Portions of this document may be illegible in electronic image products. Images are produced from the best available original document. 


\section{RADIATION DAMAGE OF A GLASS-BONDED ZEOLITE WASTE FORM USING ION IRRADIATION}

B. G. Storey, T. R. Allen

Argonne National Laboratory-West, Idaho Falls, ID 83403

\section{ABSTRACT}

Glass-bonded zeolite is being considered as a candidate ceramic waste form for storing radioactive isotopes separated from spent nuclear fuel in the electrorefining process. To determine the stability of glass-bonded zeolite under irradiation, transmission electron microscope samples were irradiated using high energy helium, lead, and krypton. The major crystalline phase of the waste form, which retains alkaline and alkaline earth fission products, loses its long range order under both helium and krypton irradiation. The dose at which the long range crystalline structure is lost is about $0.4 \mathrm{dpa}$ for helium and $0.1 \mathrm{dpa}$ for krypton. Because the damage from lead is localized in such a small region of the sample, damage could not be recognized even at a peak damage of $50 \mathrm{dpa}$. Because the crystalline phase loses its long range structure due to irradiation, the effect on retention capacity needs to be further evaluated.

\section{INTRODUCTION}

Glass-bonded zeolite is being considered as a candidate ceramic waste form for storing radioactive isotopes separated from spent nuclear fuel in the electrorefining process. During the lifetime of any nuclear waste form, mechanical and corrosion resistance properties may be degraded by gamma, beta, and alpha decay [1]. Some work has been performed on the effect of gamma and beta irradiation on the structural stability and leach rates of zeolites. No significant structural changes have been seen in zeolites irradiated with high energy gamma radiation [2-7]or low dose rate beta radiation from tritium decay [8]. Although the exchange capacity of A-type zeolites for $\mathrm{Cs}^{+}$decreases with gamma dose $[5,7,9]$, the leach resistance of salt-occluded zeolite did not differ significantly for gamma doses up to $9.9 \times 10^{8} \mathrm{rad}$ [2]. While work has been done on the effect of gamma irradiation on zeolites, the effect of alpha decay on zeolites is not as well understood.

To study the effect of alpha decay, transmission electron microscopy (TEM) samples of glassbonded zeolite loaded with lanthanides (acting as surrogate actinides and fission products) were irradiated with high energy lead, krypton, and helium in the IVEM-Tandem User Facility at Argonne National Laboratory (ANL). Work by Weber et al. [10] found that the dose to amorphization was nearly identical in both Pu-doped $\left(3 \times 10^{-9} \mathrm{dpa} / \mathrm{s}\right)$ and ion irradiated $\left(1 \times 10^{-4}\right.$ to $1 \times 10^{-3} \mathrm{dpa} / \mathrm{s}$ ) zircons $\left(\mathrm{ZrSiO}_{4}\right)$, suggesting that heavy ion beam irradiations, with a high dose rate compared to actual waste forms, can be used to simulate alpha-decay event damage in nuclear waste forms.

The energy of a typical waste form alpha particle is between 4-6 MeV. Lower energy (30 keV) helium irradiation was used to simulate the knock-on displacement damage from alpha particles. Helium ions with energies of 4-6 MeV will pass through a TEM sample and therefore are not a good simulation of the displacement damage in the waste form. The majority of the knock-on displacement damage from the helium comes at the end of range, after the helium loses most of its energy. Therefore, the displacement damage from helium is most closely simulated using low energy helium ions. Although helium ions at energies lower than $30 \mathrm{keV}$ would have been a better simulation (10 keV would have been preferred), $30 \mathrm{keV}$ was the lowest energy beam available. High energy (100 keV) lead produces similar damage to the recoil atoms from an alpha decay. Calculations using TRIM97 [11] indicate that $100 \mathrm{keV}$ lead and $90 \mathrm{keV}$ uranium (representing a typical actinide recoil particle and energy) produce damage at a similar rate. Using lead to simulate recoil damage has a potential drawback. The range of $100 \mathrm{keV}$ lead is less than the thickness of a typical TEM disc (100-200 nm) and the damage from the lead is restricted to a narrow region within the TEM disk, making the damage difficult to discern. As an alternative to the lead irradiation, a sample was irradiated with $1 \mathrm{MeV}$ krypton. 


\section{EXPERIMENT}

\section{Materials}

The glass-bonded zeolite waste form was formed in a multistep process [12] Zeolite 5A (composition in table 1) was combined with the surrogate salts listed in table 2. The salt-occluded zeolites were then mixed with P57 glass (composition in table 1) and the waste form produced in a hot isostatic press.

Table I: Zeolite and Glass Compositions (at \%)

\begin{tabular}{ccccccccc}
\hline & $\mathrm{Si}$ & $\mathrm{Al}$ & $\mathrm{B}$ & $\mathrm{Ca}$ & $\mathrm{Na}$ & $\mathrm{K}$ & $\mathrm{O}$ & $\mathrm{Cl}$ \\
\hline Zeolite 5A & 13.1 & 13.8 & --- & 5.0 & 3.9 & -- & 64.2 & $-\cdots$ \\
P57 Glass & 19.2 & 2.5 & 10.5 & $\ldots--$ & 6.2 & 0.3 & 61.2 & $-\cdots$ \\
\hline
\end{tabular}

Table II: Surrogate Salt Composition (at\%)

\begin{tabular}{cccccccccccccccc}
\hline $\mathrm{Cl}$ & $\mathrm{Li}$ & $\mathrm{K}$ & $\mathrm{Na}$ & $\mathrm{Br}$ & $\mathrm{Rb}$ & $\mathrm{Sr}$ & $\mathrm{Y}$ & $\mathrm{I}$ & $\mathrm{Cs}$ & $\mathrm{Ba}$ & $\mathrm{La}$ & $\mathrm{Ce}$ & $\mathrm{Pr}$ & $\mathrm{Nd}$ & $\mathrm{Sm}$ \\
\hline 50.5 & 26.5 & 19 & 3.1 & 0.002 & 0.034 & 0.081 & 0.042 & 0.010 & 0.178 & 0.064 & 0.057 & 0.109 & 0.054 & 0.181 & 0.028 \\
\hline
\end{tabular}

\section{Sample Preparation}

To prepare TEM samples, a bulk sample was taken from the waste form using a $1 \mathrm{~cm}$ diameter core drill. One-half $\mathrm{mm}$ slices were taken from the core drilled cylinder with a slow speed wafering saw; oil was used as the cutting lubricant. From the $0.5 \mathrm{~mm}$ thick wafers, $3 \mathrm{~mm}$ diameter disks were cored. An ultrasonic core drill was used with $\mathrm{SiC}$ and water as the cutting slurry. The $3 \mathrm{~mm}$ disks were mechanically polished on both sides to $0.08 \mathrm{~mm}$ thick; water was the grinding lubricant. A dimple was ground into the center of one side to a depth of $\sim 0.07 \mathrm{~mm}$ using a $15 \mathrm{~mm}$ diameter grinding wheel. The final step was to ion mill (Gatan PIPS) at $5^{\circ}$ with $3 \mathrm{keV}$ Ar ions at room temperature.

\section{Irradiations}

Ion irradiations were performed using the IVEM-Tandem User Facility at Argonne National Laboratory. Samples were irradiated using $100 \mathrm{keV}$ lead ions to a fluence of $10^{16} \mathrm{~Pb}^{+} / \mathrm{cm}^{2}$ (peak displacement of $51 \mathrm{dpa}$, rate of $1.3 \times 10^{12} \mathrm{~Pb}^{+} / \mathrm{cm}^{2} \mathrm{~s}$ ). A sample was irradiated with $1 \mathrm{MeV}$ krypton ions to $10^{14} \mathrm{Kr}^{++} / \mathrm{cm}^{2}$ (peak displacement of $0.11 \mathrm{dpa}$, rate of $8.2 \times 10^{11} \mathrm{Kr}^{++} / \mathrm{cm}^{2} \mathrm{~s}$ ). Samples were irradiated with helium to a maximum fluence of $2 \times 10^{16} \mathrm{He}^{+} / \mathrm{cm}^{2}$ (peak displacement of $0.80 \mathrm{dpa}$, rate of $1.1 \times 10^{12} \mathrm{He}^{+} / \mathrm{cm}^{2} \mathrm{~s}$ ). Irradiations were stopped at intermediate doses to determine the response to fluence. All irradiations were performed at room temperature. Doses were calculated using TRIM97 assuming a displacement energy of $25 \mathrm{eV}$. If the displacement energies were 35 $\mathrm{eV}$, the calculated displacements are: $0.21 \mathrm{dpa}\left(10^{16} \mathrm{He}^{+} / \mathrm{cm}^{2}\right), 37 \mathrm{dpa}\left(10^{16} \mathrm{~Pb}^{+} / \mathrm{cm}^{2}\right)$, and 0.07 dpa $\left(10^{14} \mathrm{Kr}^{++} / \mathrm{cm}^{2}\right)$. For TRIM calculations, the composition of zeolite $5 \mathrm{~A}$ was used as the composition.

\section{RESULTS}

\section{Unirradiated Characterization:}

The unirradiated material has three distinct major phases: an amorphous glass phase, a crystalline phase resulting from salt-occluded zeolite, and a crystalline lanthanide bearing phase. To a lesser extent, alumina and potassium chloride phases have been found. Microsomite, sodium chloride, and lithium aluminum silicate were also identified using $\mathrm{x}$-ray diffraction [12]. Figure 1 shows the glass, salt-occluded zeolite, and lanthanide phases distributed throughout the waste form.

The glass has an amorphous structure, shows no indication of any lanthanides and is low (< 0.2 at\%) in $\mathrm{Cl}$. The glass appears to not have interacted with the zeolite chemically, but is found in and around the zeolite phase. Lanthanide phases, dark black in appearance (in TEM bright field), 


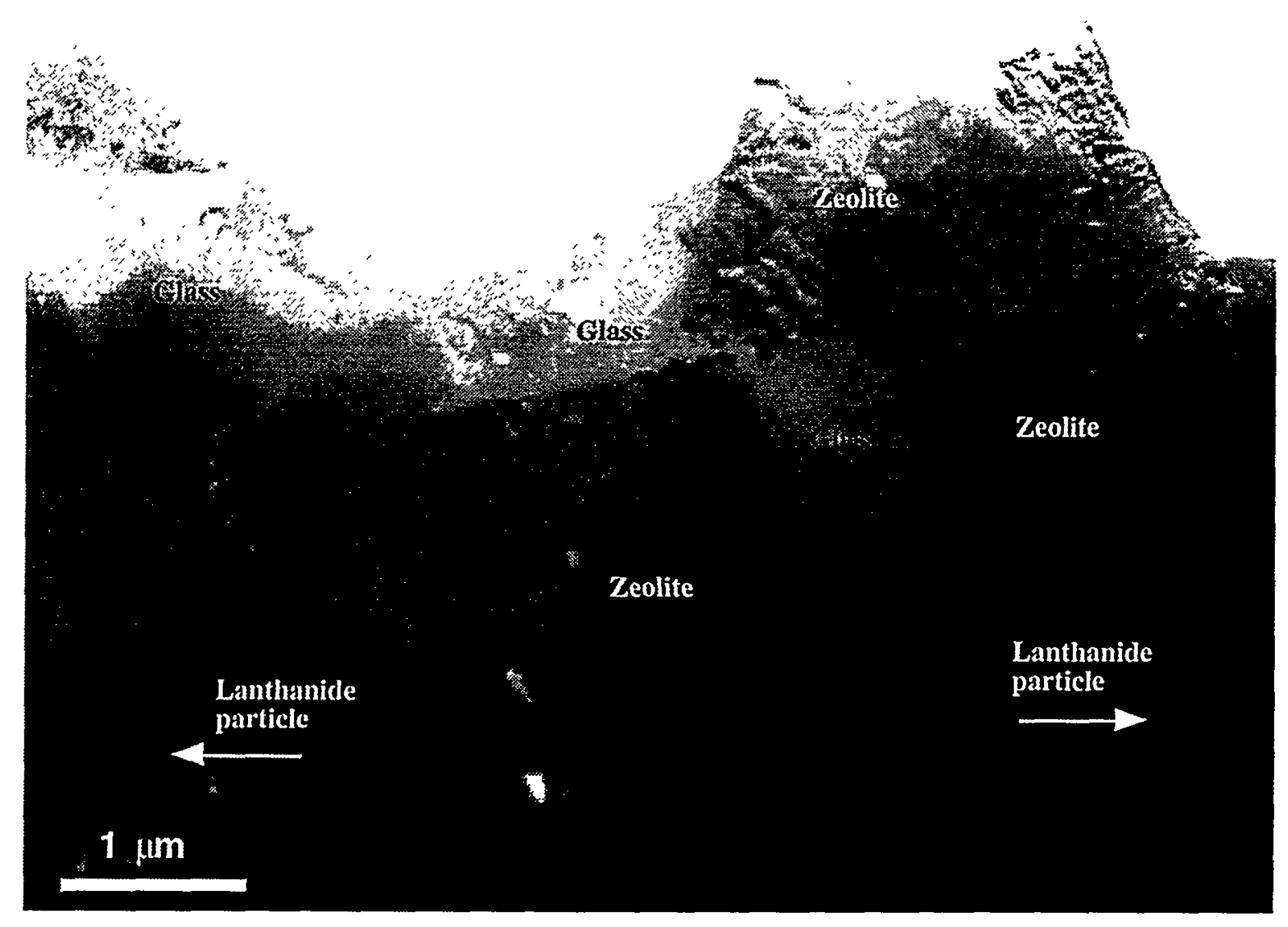

Fig. 1. TEM bright-field image of the phases in the glass-bonded zeolite waste form.

are the only place lanthanides are found at $>0.5$ at $\%$. The lanthanide particles are almost always in contact with the zeolite phase. Surrogate salts with a trivalent charge are found in the lanthanide phase.

The crystalline phase resulting from salt-occluded zeolite shows no indication of lanthanides at EDS detectability ( 0.1 at\%). Regions of this phase have been found that are low in $\mathrm{Cl}$ and most likely did not contact the salt mixture. Surrogate salts with a monovalent (Cs) or divalent (Sr) cation charge are found in the zeolite phase. The primary focus of this study is the radiation stability of this crystalline phase resulting from salt-occluded zeolite. Although electron diffraction does not show the phase to be zeolite, the phase derives from the salt-occluded zeolite and for simplicity in terminology will be identified as the zeolite phase.

\section{Effect of the Electron Beam}

The zeolite phase and the glass phase are both damaged by 100,200 , and $300 \mathrm{keV}$ electrons. Under a focused electron beam, the glass phase vaporizes and cavities form in the zeolite phase. Figure 2 shows the cavities formed in the zeolite phase. Calcium, oxygen, and potassium concentrations are greatly reduced in the damaged region. A similar effect was seen in mesolite by Yokota et al. [13]. To minimize the contribution of electron beam damage to the samples, the electron beam was turned off during ion implantation and analysis time was minimized.

\section{Helium Irradiation:}

During helium irradiation, no major changes in composition of each phase were seen. A cursory examination noted no migration of lanthanides into either the glass or zeolite phases or chlorine into the glass phases. The zeolite phase remained crystalline with no loss of long range 


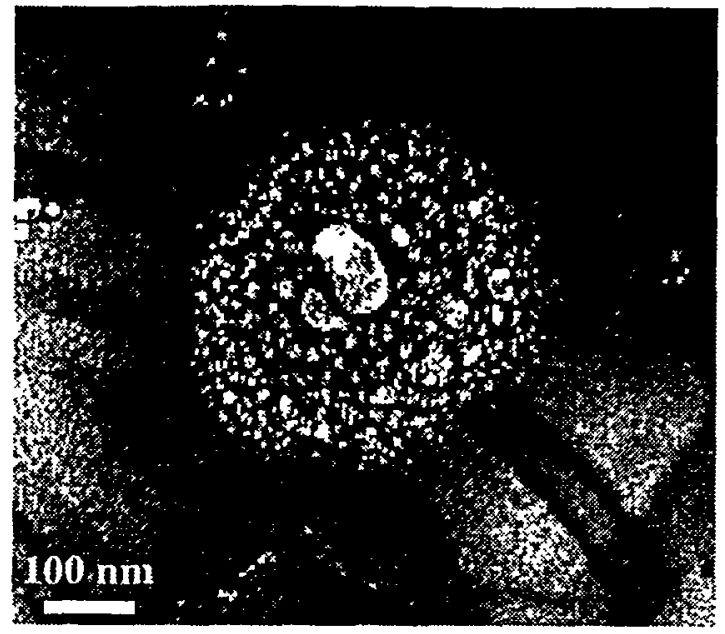

Fig. 2. TEM bright-field image of bubbles generated by a $200 \mathrm{keV}$ focused electron beam in zeolite.

order (LRO) up to $10^{15} \mathrm{He}^{+} / \mathrm{cm}^{2}$. At $2 \times 10^{16} \mathrm{He}^{+} / \mathrm{cm}^{2}$, the zeolite phase had little long range crystalline structure. Figure 3 a shows selected area diffraction patterns of the sample irradiated with helium. Diffraction patterns from samples irradiated to doses of $3 \times 10^{15}, 9 \times 10^{15}, 1.2 \times 10^{16}$, and $2 \times 10^{16} \mathrm{He} / \mathrm{cm}^{2}$ are shown. Loss of LRO due to helium is present at $0.04 \mathrm{dpa}$ and is nearly' complete by 0.8 dpa.

\section{Lead Irradiation:}

During lead irradiation, the composition of each phase also remained consistent. The zeolite phase remained crystalline with no indication of loss of LRO, even at the largest dose (51 dpa). From the lead irradiation, the zeolite appears to be fairly resistant to irradiation damage. Because the majority of the lead damage is located in a $50 \mathrm{~nm}$ thick layer (only $25-50 \%$ of the TEM sample thickness), the damage from the lead irradiation is probably not detectable. A simulation study by Miller and Ewing [14] indicates that up to thirty percent of a sample can be amorphous before the damage is discernible in a high resolution TEM image. To determine if the zeolite was truly resistant to radiation damage from ballistic collisions, irradiations were performed with $1 \mathrm{MeV}$ krypton.

\section{Krypton Irradiation:}

The zeolite phase remained crystalline with minimal loss of LRO up to $10^{13} \mathrm{Kr}^{++} / \mathrm{cm}^{2}$. At $10^{14}$ $\mathrm{Kr}^{++} / \mathrm{cm}^{2}$, the zeolite phase had little LRO with a only a small amount of crystallinity apparent. Figure $3 b$ shows selected area diffraction patterns of the sample irradiated with krypton. Diffraction patterns from samples irradiated to doses of $1 \times 10^{13}, 3 \times 10^{13}, 6 \times 10^{13}$, and $9 \times 10^{13}$ $\mathrm{Kr}^{++} / \mathrm{cm} 2$ are shown. Loss of LRO due to krypton irradiation is present at $0.01 \mathrm{dpa}$ and is nearly complete by $0.10 \mathrm{dpa}$.

\section{DISCUSSION}

Due to the longer half-lives of actinides in an actual waste form (e.g., Pu-239 has a half-life of $2.411 \times 10^{4}$ years), a waste form with approximately $3 \mathrm{wt} \% \mathrm{Pu}-239$ will reach about $1 \mathrm{dpa}$ from alpha decay after approximately 10,000 years (about $0.90 \mathrm{dpa}$ from recoil atoms and $0.1 \mathrm{dpa}$ from alpha damage). For commercial high level waste, the cumulative damage after 1000 years is about $0.25 \mathrm{dpa}$ [15]. The glass-bonded zeolite waste form is therefore expected to lose LRO during its lifetime; hence, the effect of the loss of LRO on the radioactive isotope retention ability of the glass-bonded zeolite needs to be investigated. The loss of LRO for room temperature irradiations at doses around 0.1-0.8 dpa was also seen in a detailed study of the $\mathrm{Al}_{2} \mathrm{O}_{3}-\mathrm{SiO}_{2}$ system [16]. $\mathrm{A}$ 


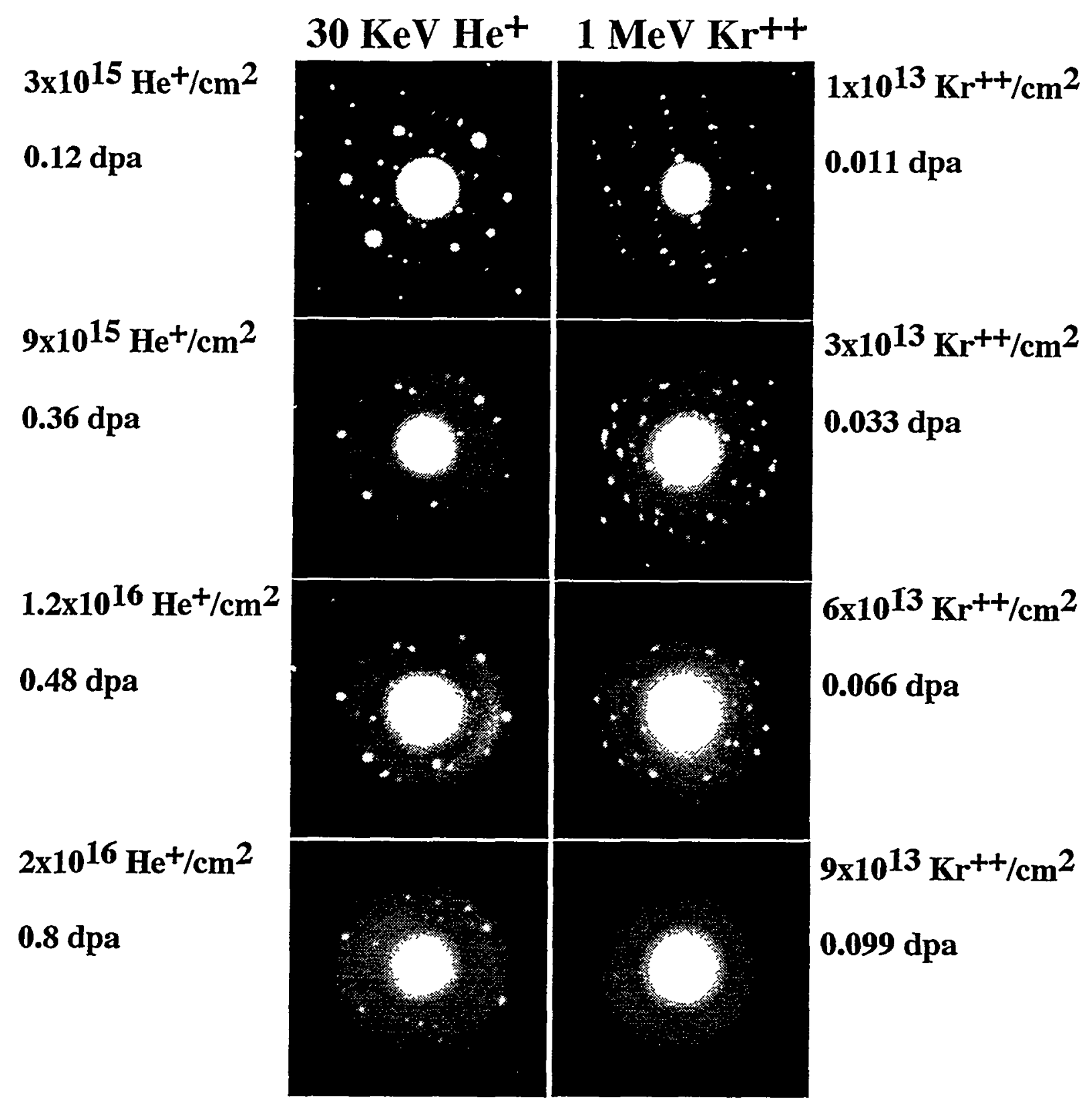

Fig. 3. Electron diffraction patterns showing the loss of crystallinity resulting from ion irradiation.

comparison of the diffraction ring in the irradiated zeolite phase and the diffraction ring from the amorphous glass suggests that the zeolite is not amorphous, but may retain medium range order or undergo nanocrystallization. If the temperature is high enough during the waste form lifetime, the zeolite phase may experience grain growth.

The primary damage mechanism in the zeolite phase is probably ballistic collisions, with ionization damage less important. The dpa at which the samples lose LRO is $0.8 \mathrm{dpa}$ for helium and $0.1 \mathrm{dpa}$ for krypton. TRM calculations indicate that the average energy transferred due to ionization is about 120 ev/atom for helium and $14 \mathrm{eV} /$ atom for krypton. The krypton, which has the smaller energy transferred due to ionization, causes a complete loss of LRO, at a lower dose. The damaged state corresponds more closely to displacement damage than ionization damage.

Because the glass-bonded zeolite is easily damaged by the electron beam, the waste form may also be susceptible to ionization damage. As a rough rule, ionization damage is important if the energy of the bombarding particle, expressed in $\mathrm{keV}$, is greater than its atomic weight [10]. Therefore, ionization could be significant in both the krypton and helium irradiations. Because the electron beam damage occurs most readily with a focused beam, sample heating or charging effects 
may also contribute to the sample damage. To determine if the zeolite phase is susceptible to ionization damage, controlled irradiations using a low current electron beam are necessary.

As noted before, other work saw little change in zeolites irradiated with high energy gamma rays. Daniels and Puri [4] found that the Cs uptake in zeolite 4A increases with increasing neutron exposure. Weakening and broadening of $x$-ray diffraction peaks with increasing neutron dose indicated framework damage. In a parallel study, gamma irradiation decreased the Cs uptake [5] Therefore, zeolites do have a different response to ballistic damage (neutrons) than ionization damage (gammas).

\section{CONCLUSIONS}

The zeolite phase of glass-bonded zeolite, responsible for radioactive isotope retention, loses LRO after irradiation with both $1 \mathrm{MeV}$ krypton and $30 \mathrm{keV}$ helium at comparable doses. The zeolite phase starts to lose LRO at around 0.01-0.04 dpa and is nearly amorphous by 0.1-0.8 dpa. Because the waste form is expected to reach displacements of greater than $0.1 \mathrm{dpa}$, the consequences of the loss of LRO on leach rates need to be investigated.

Lanthanides, acting as actinide and fission product surrogates, are not contained in the zeolite phase, but form a separate phase. Therefore, damage from the recoil atom in an alpha decay is only expected to damage the lanthanide phase and any zeolite within about $30-40 \mathrm{~nm}$ from the edge of the lanthanide phase. This localized damage in the zeolite phase around the lanthanide phase could lead to volume changes and possible phase separation and cracking. Since the range of the alpha particle is greater than the average spacing of the lanthanide phases, damage from the alpha particle will be distributed throughout the zeolite phase.

\section{ACKNOWLEDGMENTS}

The authors are grateful to the staff at the IVEM-Tandem facility at Argonne National Laboratory for their assistance during ion irradiations. Work supported under contract W-31-109Eng-38 with the US Department of Energy.

\section{REFERENCES}

1. W.J. Weber and F.P. Roberts, Nucl. Technol. 60, 178 (1983).

2. M.A. Lewis, D.F. Fischer, and L.J. Smith, J. Am. Ceram. Soc. 76, 2826 (1993).

3. K.J. Swyler and R.E. Barletta, Irradiation of Zeolite Ion-Exchange Media, BNL-NUREG51551, December 1983.

4. E.A. Daniels and M. Puri, Radiat. Eff. 90, 205 (1985).

5. E.A. Daniels and M. Puri, Radiat. Phys. Chem. 21, 225 (1986).

6. T. El-Nabarawy and G.A. El-Shobaky, Thermochimica Acta 111, 249 (1987).

7. H. López, M.T. Olguín, P. Bosch, and S. Bulbulian, J. Radioanal. Nucl. Chem. Lett. 200, 19 (1995).

8. J.L. Maienschein, F.E. McMurphy, and F.S. Uribe, Fusion Technology 14, 775 (1988).

9. G.L. Palau and K.K.S. Pillay, Trans. Am. Nucl. Soc. 43, 113 (1982).

10. W.J. Weber, R.C. Ewing, and L. Wang, J. Mater. Res. 9, 688 (1994).

11. J.F. Ziegler and J.P. Biersack, TRIM (IBM, Yorktown, NY, 1997).

12. S.M. Frank, presented at the 1997 MRS Fall Meeting, Boston MA, 1997 (unpublished).

13. Y. Yokota, H. Hashimoto, and T. Yamaguchi, J. Elec. Micros. 48, 203 (1990).

14. M.L. Miller and R.C. Ewing, Ultramicroscopy 48, 203 (1992).

15. R.C. Ewing, W.J. Weber, and J.F.W. Clinard, Prog. Nucl. Ener. 2, 63 (1995).

16. S.X. Wang, L.M. Wang, and R.C. Ewing, J. Appl. Phys. 81, 587 (1997). 